\title{
Healthcare institutions' recommendation regarding the use of FFP-2 masks and SARS-CoV-2 seropositivity among healthcare workers: a multicenter longitudinal cohort study
}

Katarzyna Szajek ${ }^{1}$ Felix Fleisch², Sandra Hutter ${ }^{3}$, Martin Risch $^{3}$, Theresa Bechmann ${ }^{4}$, Valerie A. Luyckx ${ }^{5}$, Sabine Güsewell ${ }^{6}$, Cédric Hirzel ${ }^{7 \dagger}$, Alexia Cusini ${ }^{2 *}$ and AMICO Study GroupAMICO Study Group

\begin{abstract}
Background: Health care workers (HCW) are heavily exposed to SARS-CoV-2 from the beginning of the pandemic. We aimed to analyze risk factors for SARS-CoV-2 seroconversion among HCW with a special emphasis on the respective healthcare institutions' recommendation regarding the use of FFP-2 masks.

Methods: We recruited HCW from 13 health care institutions ( $\mathrm{HCl}$ ) with different mask policies (type IIR surgical face masks vs. FFP-2 masks) in Southeastern Switzerland (canton of Grisons). Sera of participants were analyzed for the presence of SARS-CoV-2 antibodies 6 months apart, after the first and during the second pandemic wave using an electro-chemiluminescence immunoassay (ECLIA, Roche Diagnostics). We captured risk factors for SARS-CoV-2 infection by using an online questionnaire at both time points. The effects of individual COVID-19 exposure, regional incidence and FFP-2 mask policy on the probability of seroconversion were evaluated with univariable and multivariable logistic regression.

Results: SARS-CoV-2 antibodies were detected in 99 of 2794 (3.5\%) HCW at baseline and in 376 of 2315 (16.2\%) participants 6 months later. In multivariable analyses the strongest association for seroconversion was exposure to a household member with known COVID-19 (aOR: 19.82, 95\% Cl 8.11-48.43, $p<0.001$ at baseline and aOR: 8.68, 95\% Cl 6.13-12.29, $p<0.001$ at follow-up). Significant occupational risk factors at baseline included exposure to COVID-19 patients (aOR: $2.79,95 \% \mathrm{Cl} 1.28-6.09, p=0.010$ ) and to SARS-CoV-2 infected co-workers (aOR: 2.50, 95\% Cl 1.52-4.12, $p<0.001$ ). At follow up 6 months later, non-occupational exposure to SARS-CoV-2 infected individuals (aOR: 2.54 , $95 \% \mathrm{Cl} 1.66-3.89 p<0.001)$ and the local COVID-19 incidence of the corresponding $\mathrm{HCl}(\mathrm{aOR}: 1.98,95 \% \mathrm{Cl} 1.30-3.02$, $p=0.001$ ) were associated with seroconversion. The healthcare institutions' mask policy (surgical masks during usual exposure vs. general use of FFP-2 masks) did not affect seroconversion rates of HCW during the first and the second pandemic wave.
\end{abstract}

\footnotetext{
*Correspondence: alexia.cusini@ksgr.ch

${ }^{\dagger}$ Cédric Hirzel and Alexia Cusini authors contributed equally to this work

2 Division of Infectious Diseases, Cantonal Hospital of Grisons, 7000 Chur, Switzerland

Full list of author information is available at the end of the article

AMICO Study Group authors are listed in the Acknowledgements.
} permits use, sharing, adaptation, distribution and reproduction in any medium or format, as long as you give appropriate credit to the original author(s) and the source, provide a link to the Creative Commons licence, and indicate if changes were made. The images or other third party material in this article are included in the article's Creative Commons licence, unless indicated otherwise in a credit line to the material. If material is not included in the article's Creative Commons licence and your intended use is not permitted by statutory regulation or exceeds the permitted use, you will need to obtain permission directly from the copyright holder. To view a copy of this licence, visit http://creativecommons.org/licenses/by/4.0/. The Creative Commons Public Domain Dedication waiver (http://creativeco mmons.org/publicdomain/zero/1.0/) applies to the data made available in this article, unless otherwise stated in a credit line to the data. 
Conclusion: Contact with SARS-CoV-2 infected household members was the most important risk factor for seroconversion among HCW. The strongest occupational risk factor was exposure to COVID-19 patients. During this pandemic, with heavy non-occupational exposure to SARS-CoV-2, the mask policy of HCls did not affect the seroconversion rate of HCWs.

Keywords: SARS-CoV-2, Healthcare workers, Seroconversion, FFP-2 and surgical masks, Mask policy

\section{Introduction}

Health care workers $(\mathrm{HCW})$ are engaged at the frontline of the COVID-19 pandemic and are thereby heavily exposed to SARS-CoV-2. From the beginning of the pandemic, several studies have investigated the risk for $\mathrm{HCW}$ for infections with SARS-CoV-2. While some studies showed low infection rates among HCW indicating that the implemented protection measures were effective [1-4], others studies revealed high infection rates among $\mathrm{HCW}$ [5-11]. The most frequently identified risk factors for transmission of SARS-CoV-2 to HCW include working at dedicated COVID-19 units [6, 7], having either direct contact with infected patients $[8,9]$, or infected co-workers $[9,11]$ and being exposed to infected household members $[8,10,11]$.

There is still an ongoing debate about the mode of transmission of SARS-CoV-2 by respiratory particles. Some advocate that transmission of SARS-CoV-2 mainly occurs by droplets $[12,13]$ while others highlight the importance of aerosols [14, 15]. Accordingly, there is inconsistency in recommendations regarding the use of different types of masks for protection of HCW. The World Health Organization (WHO), Public Health England, and the Swiss National Centre for Infection Control (Swissnoso) recommended the use of surgical masks, with the exception for exposure during aerosol-generating procedures (AGP) [16-18]. In contrast, the United States Centers for Diseases Control and Prevention (CDC), the European Centre for Disease Prevention and Control (ECDC), and the German Robert Koch Institute recommended universal use of filtering face piece class-2 (FFP-2) masks for protection against airborne transmission [19-21]. Indeed, recent publications suggest that aerosols arise not only during AGP and therefore FFP-2 masks might be advantageous in virus-rich indoor environments including medical centres and hospitals [22-24].

Despite the official recommendation in Switzerland to restrict the use of FFP-2 masks to AGP, about half of health care institutions (HCI) in the Canton of Grisons opted for a general use of FFP-2 masks. We therefore took the opportunity of this particular situation to analyse the effect of the healthcare institutions' mask policy on SARS-CoV-2 seroconversion rates among HCW.
Thus, the aim of our study was to assess risk factors for SARS-CoV-2 seroconversion among HCW in the canton of Grisons, Switzerland during the first and the second epidemic wave, with a special emphasis on the healthcare institution's recommendation regarding the use of FFP-2 masks.

\section{Methods}

\section{Participants and setting}

We performed a multicenter prospective cohort study including $13 \mathrm{HCI}$ caring for patients with COVID-19 in the canton of Grisons, Switzerland. The selected HCI consisted of one referral center (provincial hospital; 330 bed medical center with integrated intensive care unit), nine small primary care hospitals (average bed capacity: 33 beds), two rehabilitation centers (average bed capacity: 108 beds) and one psychiatric clinic (capacity of 240 beds). We invited all health care employees ( $\geq 16$ years of age) in the selected $\mathrm{HCI}$ to participate in the study.

Study participants underwent serological SARS-CoV-2 testing at baseline and concomitantly completed a questionnaire to assess exposure to anticipated risk factors for SARS-CoV-2 infection after the first epidemic wave (sampling provincial hospital: June 8-June 26, 2020; sampling other HCIs: July 20-August 13, 2020). The study participants underwent the same procedure during the second pandemic wave (follow-up sampling provincial hospital: January 4-February 19, 2021; follow-up sampling other HCIs: February 1-February 19, 2021). The timeline of the study is pictured in Fig. 1. The incidence of COVID19 per 100,000 inhabitants in the different study regions was retrieved from the health department of the canton Grisons [25]. The study was approved by the ethics committee of the canton Zurich (BASEC-No.: 2020-01322). We obtained written informed consent from all participants before enrollment.

\section{Serologic testing}

We collected serum $(10 \mathrm{~mL})$ at baseline and follow-up. SARS-CoV-2 nucleocapsid (N) antibody concentrations were determined using a commercially available electrochemiluminescence immunoassay (ECLIA, Elecsys ${ }^{\circledR}$ Anti-SARS-CoV-2, Roche, Basel, Switzerland), which was run on a COBAS 6000 analyzer (Roche, Rothkreuz, Swizterland). Seropositivity was defined according to 


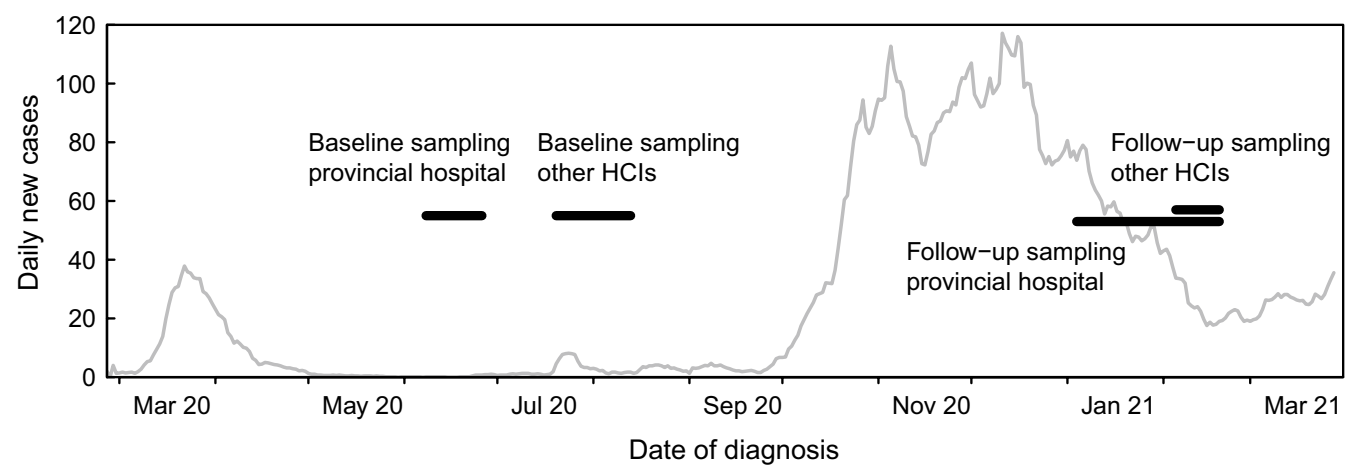

Fig. 1 Timeline of the study. The pandemic in the Canton of Grisons from March 2020 to March 2021 is represented by the 7-day running mean of daily numbers of new COVID-19 cases. Horizontal bars indicate the time of baseline and follow up sampling in the participating health care institutions ( $\mathrm{HCls}$ )

the manufacturers' instructions (cutoff index $(\mathrm{COI})>1$ ) and seroconversion was defined as the first detection of SARS-CoV-2 antibodies above the threshold. The manufacturer-reported sensitivity and specificity ( $>14$ days after PCR positivity) of the assay is $100 \%$ (95\% CI $88.1-$ $100 \%$ ) and $99.80 \%$ (95\% CI 99.69-99.88), respectively [26].

\section{Online questionnaire}

To assess risk factors for seroconversion, participants were asked to complete an online questionnaire at each time point of serological sampling. We requested participants to fill in the questionnaire at both time points to make sure that changes of risk factors (e.g. occupational exposure to COVID-19 patients) were correctly captured over time. In the baseline questionnaire, study participants were asked to report their possible exposure to SARS-CoV-2 from the beginning of the pandemic until baseline and in the follow-up questionnaire, they were explicit asked to report their possible exposure occurring between baseline and follow up. Variables of interest included sex, age, type of ABO blood group, type of occupation, level of employment, occupational exposure to patients (with or without COVID-19), occupational exposure to SARS-CoV-2 infected co-workers, household and other non-occupational exposure to individuals with COVID-19. Additionally, self-reported results of previously performed SARS-CoV-2 nasopharyngeal swabs were collected (see AMICO Questionnaire in the Additional file 1).

\section{Preventive measures for healthcare workers}

According to the guidelines of the National Centre for Infection Control [16], seven HCI (one secondary care hospital, five primary care hospitals and one rehabilitation clinic) implemented recommendations to use surgical face masks type IIR during usual exposures and restricted the use of FFP-2 masks to AGP. The remaining six other institutions (four primary care hospitals, one rehabilitation clinic and one psychiatric clinic) recommended the general use of FFP-2 masks for all contacts with COVID-19 patients. Other preventive measures for HCW were similar among institutions and included the use of gloves, gowns and goggles during exposure to COVID-19 patients, hand-hygiene measures and social distancing following the Swiss guidelines released by Swissnoso [18] and the Federal Office of Public Health (FOPH) [27]. The compliance of the HCW with the institutional mask policy and the other recommended protective measure was not systematically assessed as part of the study.

No health care institution reported an important lack of personal protective equipment.

\section{Statistical analysis}

Seropositivity rates were reported as proportions. Associations between potential risk factors (personal and professional characteristics, individual COVID-19 exposure, regional incidence, FFP-2 mask policy) and seroconversion were assessed by calculating the proportion of participants with seroconversion for each level of these factors. Odds ratios (OR) and 95\% confidence intervals $(95 \% \mathrm{CI})$ for comparisons between factor levels were determined by logistic regression, and $p$ values from Wald tests are reported. For factors determined at institution level (regional incidence, FFP-2 mask policy), regression models included institutions as random effect. The combined effects of individual COVID-19 exposure, regional incidence and FFP-2 mask policy on the probability of seroconversion were evaluated with multivariable logistic mixed-effects models including institutions as random effect. To account for possible confounders, 
models additionally included factors that showed a significant association with seroconversion at least at one time point, excluding factors that were recorded only for a subgroup of participants. Statistical analysis was performed using the software R, version 4.0.2 (R Foundation for Statistical Computing, Vienna, 2020, www.R-project. org).

\section{Results}

\section{Study population}

We included $2794 \mathrm{HCW}$ from 13 healthcare institutions of the canton Grisons, Switzerland. This corresponds to $49 \%$ of all $\mathrm{HCW}$ employed in the participating $\mathrm{HCI}$. SARS-CoV-2 serological testing was performed for $100 \%$ (2794/2794) of participants at baseline, and for $83 \%$ (2315/2794) of participants at follow up (Fig. 2).

Baseline characteristics of study participants according to the HCIs mask policy are summarised in Table 1 . The proportion of study participants with occupational exposure to patients with COVID-19 was similar among HCI with different mask policies. The mean regional incidence of COVID-19 at baseline and at follow-up was higher for $\mathrm{HCI}$ that recommended general use of FFP-2 masks. An overview of all HCI participating in the AMICO is provided in in the Additional file 1: Table S1.

\section{Risk factors associated with SARS-CoV-2 seroconversion}

SARS-CoV-2 serology was positive in 3.5\% (99/2794) of participants at baseline and in $16.2 \%(376 / 2315)$ of participants at follow-up. Eighty-eight participants with positive serology at baseline participated in the follow-up, of whom 97.7\% (86/88) remained seropositive. Additional $13 \%(290 / 2227)$ of participants, who were seronegative at baseline, seroconverted until the time of the follow-up.

In univariable analysis, contact to a SARS-CoV-2 infected household member was the strongest risk factor for seroconversion (OR: 20.70, 95\% CI 9.43-43.99, $p<0.001$, at baseline and OR: 9.02, 95\% CI 6.43-12.67,

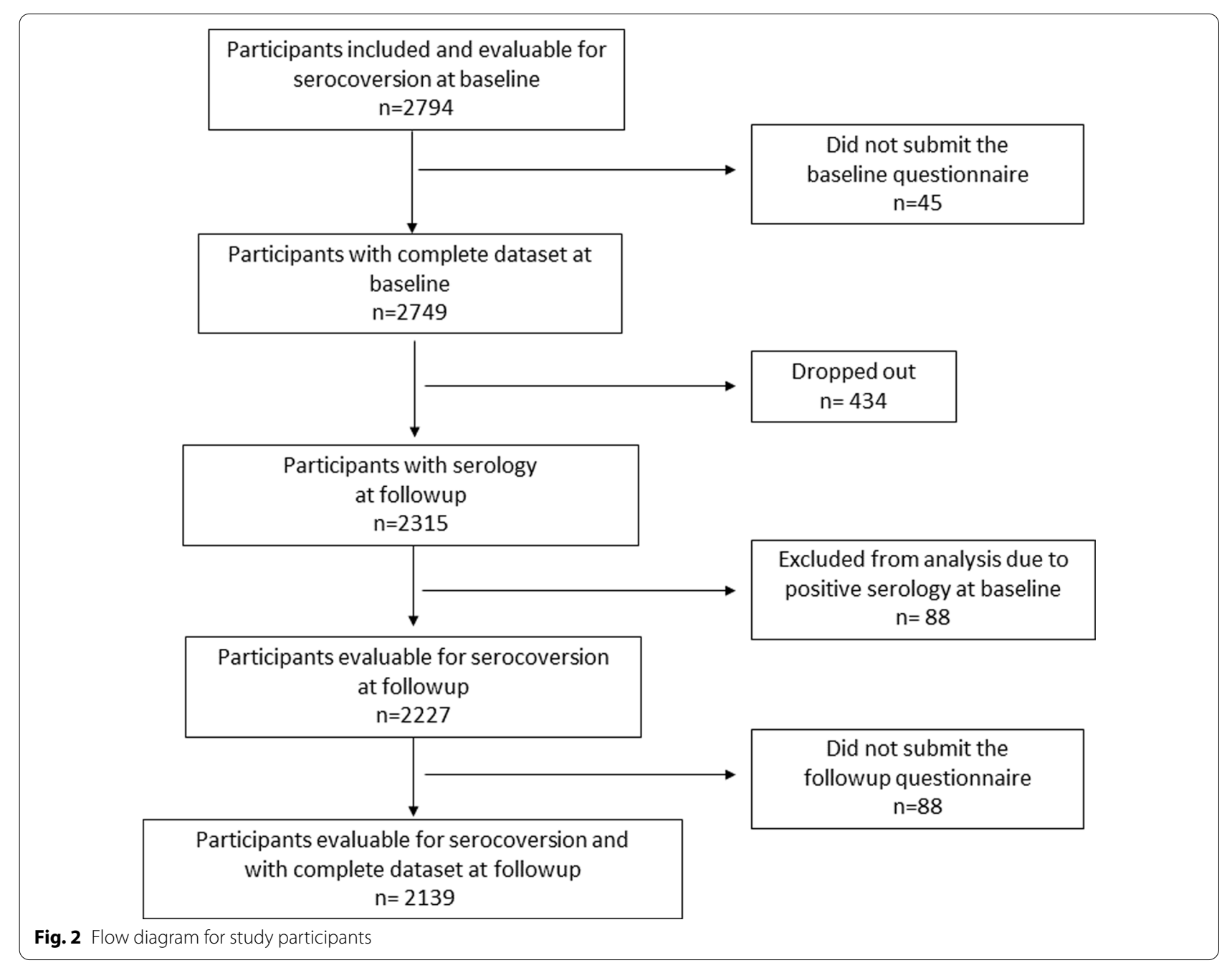


Table 1 Characteristics of study participants according to the mask policy of the respective health care institution

\begin{tabular}{|c|c|c|}
\hline & $\begin{array}{l}\text { FFP-2 masks recommended exclusively for aerosol } \\
\text { generating procedures in patients with COVID-19 }\end{array}$ & $\begin{array}{l}\text { FFP- } 2 \text { masks recommended for } \\
\text { all interactions with patients with } \\
\text { COVID-19 }\end{array}$ \\
\hline Number of health care institutions & 7 & 6 \\
\hline Number of participants $(n=2794)$ & 1993 & 801 \\
\hline Age, median (IQR) & $42(31-52)$ & $45(33-54)$ \\
\hline Sex: n (\%) female & $1579(79.2 \%)$ & $618(77.2 \%)$ \\
\hline \multicolumn{3}{|l|}{ Profession } \\
\hline Employee without patient exposure & $406(20.4 \%)$ & $153(19.1 \%)$ \\
\hline Nurse & $823(41.3 \%)$ & $295(36.8 \%)$ \\
\hline Physician & $305(15.3 \%)$ & $71(8.9 \%)$ \\
\hline Other employee with patient exposure & $459(23.0 \%)$ & $282(35.2 \%)$ \\
\hline Employee in ICU & $168(8.4 \%)$ & $19(2.4 \%)$ \\
\hline Employee in COVID-19 ward & $186(9.3 \%)$ & $60(7.5 \%)$ \\
\hline Employee in emergency unit & $309(15.5 \%)$ & $87(10.9 \%)$ \\
\hline \multicolumn{3}{|l|}{ Exposure at baseline $(n=2757)$} \\
\hline \multicolumn{3}{|l|}{ Type of patient exposure } \\
\hline No patient exposure & $601(30.2 \%)$ & $244(30.5 \%)$ \\
\hline Exposure to non-COVID-19 patients & $827(41.5 \%)$ & $384(47.9 \%)$ \\
\hline Exposure to COVID-19 patients & $532(26.7 \%)$ & 169 (21.1\%) \\
\hline Exposure to SARS-CoV2 infected co-worker & $297(14.9 \%)$ & $86(10.7 \%)$ \\
\hline $\begin{array}{l}\text { Non-occupational exposure to SARS-CoV2 infected } \\
\text { person }\end{array}$ & $58(2.9 \%)$ & $33(4.1 \%)$ \\
\hline \multicolumn{3}{|l|}{ Exposure at follow up $(n=2139)$} \\
\hline \multicolumn{3}{|l|}{ Type of patient exposure } \\
\hline No patient exposure & 499 (30.5\%) & $210(35.5 \%)$ \\
\hline Exposure to non-COVID-19 patients & $339(20.7 \%)$ & $154(26.1 \%)$ \\
\hline Exposure to COVID-19 patients & $729(44.6 \%)$ & $208(35.2 \%)$ \\
\hline Exposure to SARS-CoV2 infected co-worker & $322(19.7 \%)$ & $123(20.8 \%)$ \\
\hline $\begin{array}{l}\text { Non-occupational exposure to SARS-CoV2 infected } \\
\text { person }\end{array}$ & $161(9.8 \%)$ & $70(11.8 \%)$ \\
\hline $\begin{array}{l}\text { Cumulative regional incidence per } 100,000 \text { inhabitants } \\
\text { (July 2020/March 2021), mean }\end{array}$ & $340 / 5298$ & $539 / 6432$ \\
\hline
\end{tabular}

$p<0.001$, at follow-up). Occupational exposure to COVID-19 patients was also associated with seroconversion at both time points. (OR: 3.23, 95\% CI 1.89-5.76, $p<0.001$ at baseline and OR: 1.73, 95\% CI 1.29-2.33, $p<0.001$ at follow-up). Conversely, the healthcare institutions'FFP-2 mask policy was not significantly associated with seroconversion for SARS-CoV-2 (OR: 0.7, 95\% CI $0.20-2.40, p=0.567$ at baseline and OR: $1.14,95 \%$ CI $0.60-2.16, p=0.693$ at follow up). An additional subgroup analysis of HCW with direct exposure to COVID19 patients did not reveal an association between seroconversion and the healthcare institutions' mask policy (Additional file 1: Table S2). Occupational risk factors for seroconversion at baseline and at follow-up included: working as a nurse (OR: 2.38, 95\% CI 1.28-4.85, $p=0.010$ at baseline and OR: 1.72, 95\% CI 1.23-2.46, $p=0.002$ at follow-up), working in COVID-19 specific wards (OR:
4.19, 95\% CI 2.57-6.69, $p<0.001$ at baseline and OR: $1.80,95 \%$ CI 1.28-2.51, $p=0.001$ at follow-up) and exposure to a SARS-CoV-2 positive co-worker (OR: 4.64, 95\% CI $3.04-7.04, p<0.001$ at baseline and OR: $1.44,95 \%$ CI 1.07-1.92, $p=0.015$ at follow-up). A high regional incidence of COVID-19 (OR: 2.06, 95\% CI 1.10-3.89, $p=0.025)$ and non-occupational contact with SARSCoV-2 positive individuals (OR: $2.64,95 \%$ CI 1.72-3.95, $p<0.001$ ) were only associated with seroconversion at the follow-up measurement (Table 2).

In multivariable analyses contact with a SARS-CoV-2 infected household member was still strongly associated with seroconversion (aOR: 19.82, 95\% CI 8.11-48.43, $p<0.001$ at baseline and aOR: 8.68, 95\% CI 6.13-12.29, $p<0.001$ at follow-up). Occupational risk factors at baseline included exposure to COVID-19 patients (aOR: $2.79,95 \%$ CI 1.28-6.09, $p=0.010$ ) and contact with a 


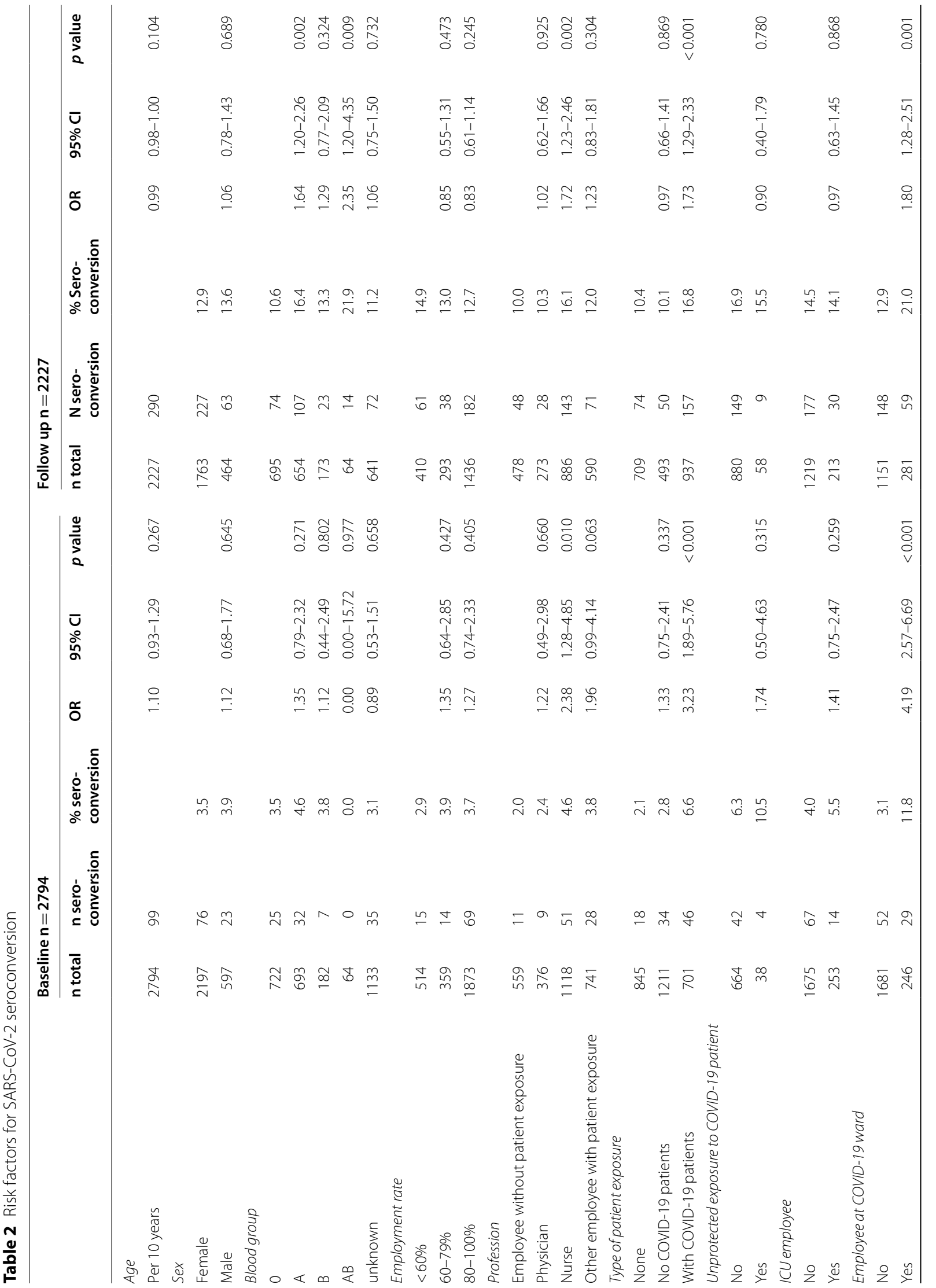




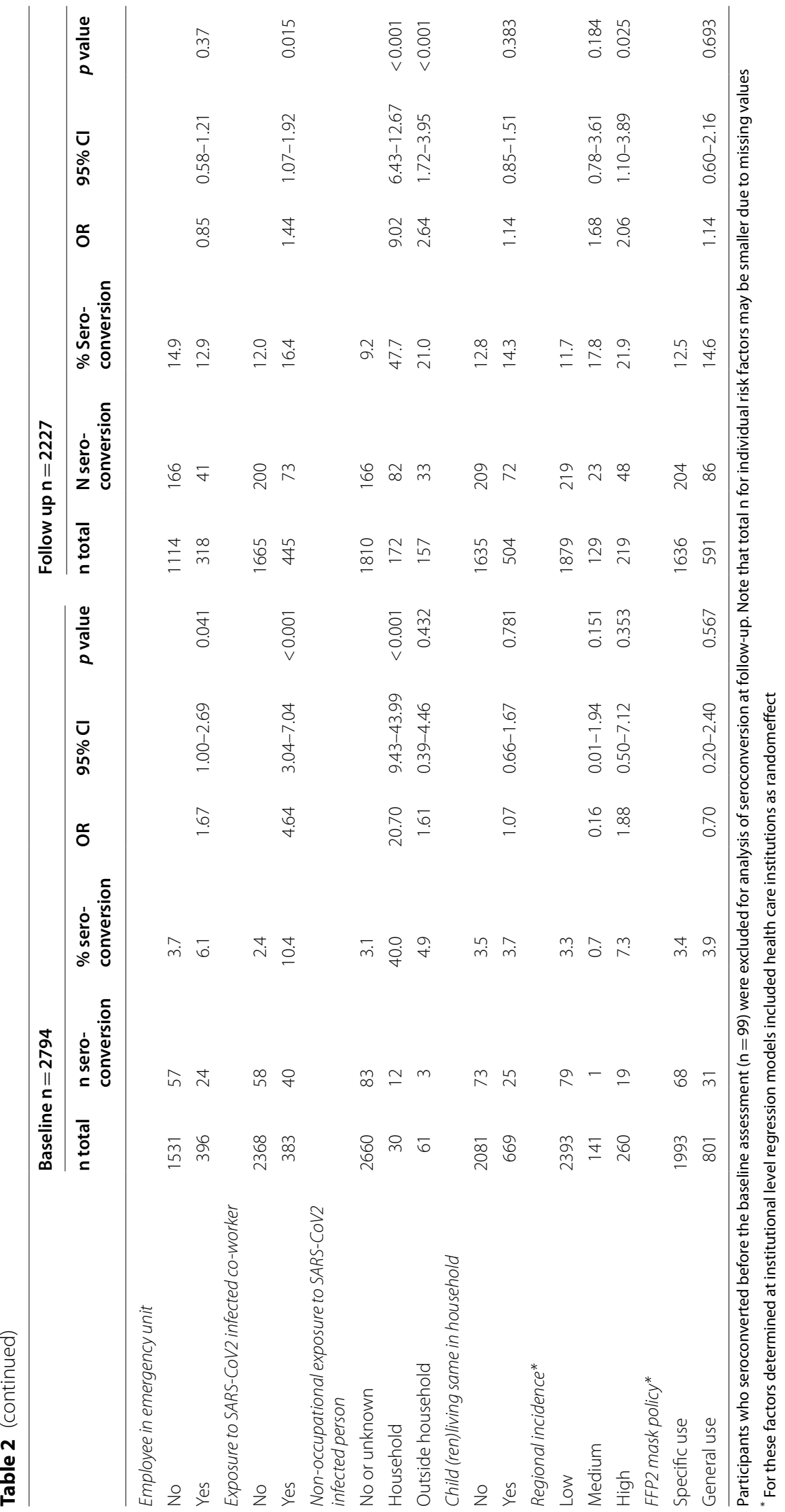


SARS-CoV-2 positive co-worker (aOR: $2.50,95 \% \mathrm{CI}$ $1.52-4.12, p<0.001)$. In contrast, at follow-up, nonoccupational contact with SARS-CoV-2 positive individuals (aOR: 2.54, 95\% CI 1.66-3.89, $p<0.001$ ) and the COVID-19 incidence in the region of the HCI (aOR: 1.98, 95\% CI 1.30-3.02, $p=0.001$ ) were associated with an increased risk for seroconversion. Interestingly, healthcare workers with the blood group $\mathrm{O}$ were less likely to seroconvert (aOR: 0.7, 95\% CI 0.52-0.94, $p=0.018$ ). Of note, the healthcare institutions' mask policy was neither associated with seroconversion at baseline nor at the time of follow-up (Figs. 3 and 4). Even in the subgroup of healthcare workers with direct exposure to SARS-CoV-2 infected patients, we did not find an association between seroconversion and the healthcare institutions' mask policy (Additional file 1: Table S3).

\section{Association between SARS-CoV-2 PCR test result and seroconversion}

Only 17\% (479/2749) of participants underwent a nasopharyngeal swab with subsequent SARS-CoV-2 PCR testing before the baseline assessment. At the time of the
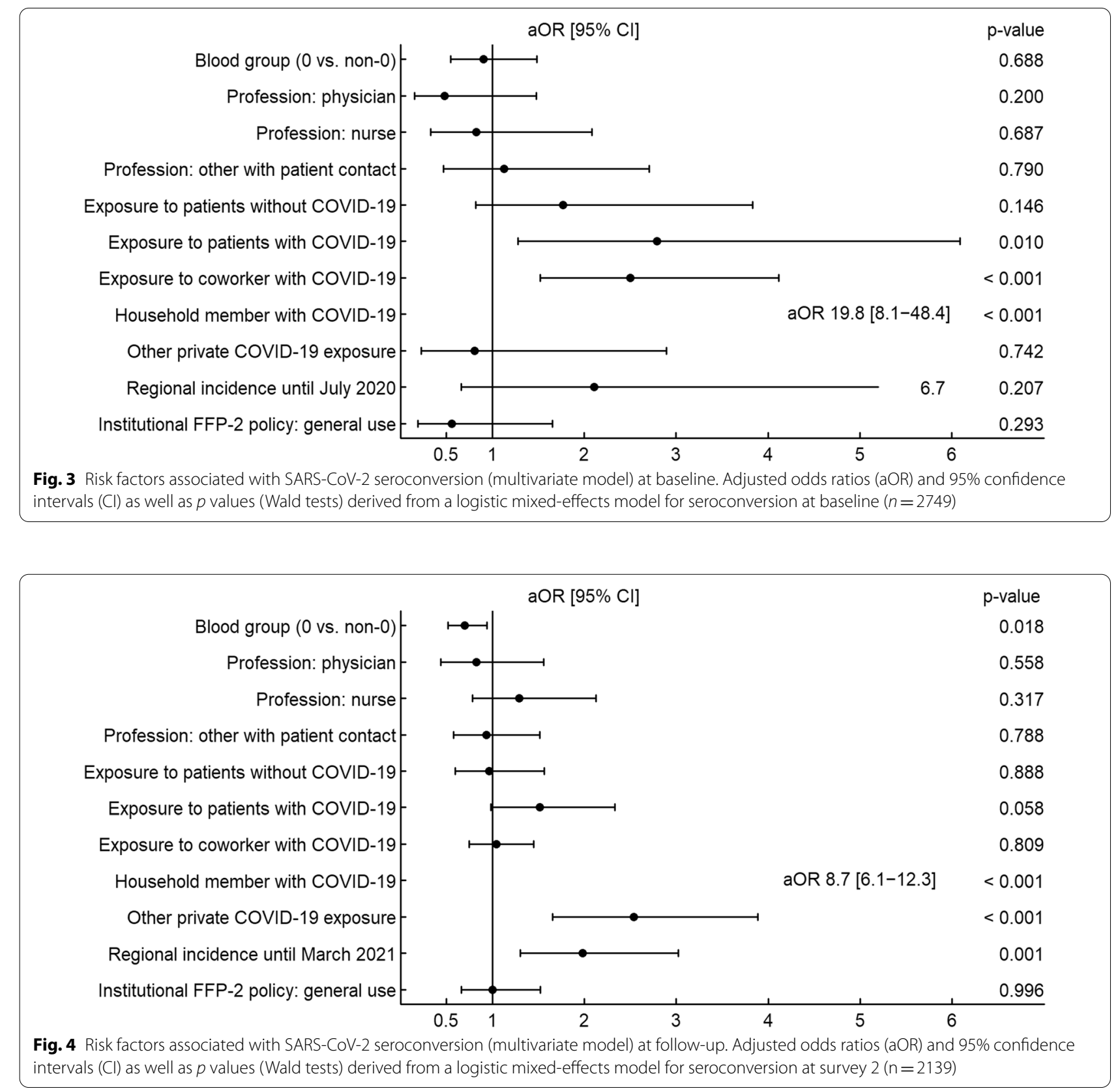
follow-up 59\% (1272/2139) of participants had SARS$\mathrm{CoV}-2$ PCR testing. Serological testing was positive in 93\% (54/58) of participants with positive SARS-CoV-2 PCR at baseline and in 95\% (227/239) of participants at follow-up. 45\% (45/99) of participants with seroconversion at baseline and 21\% (63/290) with seroconversion at follow-up did not report previous positive PCR test results.

\section{Discussion}

In this multicentre prospective cohort study, one sixth of participating HCW were seropositive for SARS$\mathrm{CoV}-2$ as by early 2021 . The most important risk factor for seroconversion was household exposure to a SARS$\mathrm{CoV}-2$ infected individual. Occupational risk factors such as exposure to COVID-19 patients and contact with SARS-CoV-2 positive co-workers were associated with seroconversion during the first pandemic wave. During the second wave of the pandemic non-occupational contact with persons with SARS-CoV-2 infection and the regional COVID-19 incidence were identified as risk factors for seroconversion. Interestingly, the healthcare institutions' mask policy (surgical mask vs. FFP-2 mask) did not affect the risk of $\mathrm{HCW}$ to seroconvert.

Household exposure to a confirmed COVID-19 case has been reported to be a major risk factor for seroconversion among HCW in previous studies $[8,10,11]$. However, it is difficult to dissect the exact sequence of infections as asymptomatically infected HCW may also transmit the virus to household members who subsequently develop symptomatic disease. A recent Scottish study reported a two-fold increased risk for hospital admissions of household members of HCW compared to the general population [28], suggesting that $\mathrm{HCW}$ may play an important role in the spread of SARS-CoV-2.

An interesting finding of our study is the shift from occupation related infections at baseline to non-occupational infections at follow-up. This finding might be related to the adaption of the general preventive measures against COVID-19 in Switzerland after the first pandemic wave: during the first wave, the imposed lockdown reduced social life to a minimum. This might have limited non-occupational transmission significantly. In the later course, loosening the pandemic measures might have led to more non-occupational transmissions among $\mathrm{HCW}$. Accordingly, we found an association between non-occupational contact with persons with SARS-CoV-2 and the regional COVID-19 incidence and seroconversion at follow-up but not at baseline.

A factor that may further have reduced occupational transmissions over time is the increasing number of $\mathrm{HCW}$ who reported to have performed a diagnostic PCR test for SARS-CoV-2 from $17 \%$ at baseline to $59 \%$ at follow up. Accordingly, the number of missed SARS$\mathrm{CoV}-2$ infections prior to serology decreased from 45 to $21 \%$. Testing of $\mathrm{HCW}$ and consequent isolation of infected individuals may have also reduced occupation related transmission over time.

In our study, HCW with direct exposure to COVID-19 patients were at increased risk for seroconversion during the first pandemic wave. This finding is consistent with previous reports $[8,9]$ and it might reflect important limitations of protective measures probably due to unintentional breaches of safe practice standards or insufficient knowledge in the handling of the personal protective equipment.

Interestingly, we did not find a significant association between the healthcare institutions' FFP-2 mask policy and the risk for seroconversion among $\mathrm{HCW}$. Even in the subgroup of $\mathrm{HCW}$ with direct exposure to COVID-19 patients, we did not find an association. In this point our results differs from those recently published by Haller et al. who reported lower seroconversion rates among $\mathrm{HCW}$ with frequent ( $>20$ patients) COVID-19 exposure, who preferentially used FFP-2 masks [29]. In the study of Haller et al. the authors assessed the use of different mask types individually for each employee, while our study focussed on the mask recommendation on an institutional level.

We observed that HCW with blood group $\mathrm{O}$ were less likely to have detectable SARS-CoV-2 antibodies. Several previous studies have also identified an association of the $\mathrm{ABO}$ blood group type and the susceptibility to COVID19 with a protective effect of blood group $\mathrm{O}$ [30].

One strength of our study was the comprehensive enrolment of a high proportion of $\mathrm{HCW}$ at thirteen $\mathrm{HCIs}$ located in the same geographical region. The different FFP-2 mask policies of these institutions, which remained unchanged over time, allowed us to analyse comprehensively their impact on the HCWs' risk for seroconversion. Additionally, we followed participants longitudinally and performed serological measurements after the first and during the second pandemic wave. This allowed us to analyse the shift in risk factors for seroconversion among $\mathrm{HCW}$ during the course of the pandemic.

Some limitations of our study deserve discussion. Infections with SARS-CoV-2 were defined as seroconversion and were methodologically captured with delay. Potentially memory bias in reporting exposure and behaviours may have influenced the results. Moreover, causality between reported exposures and seropositivity can only be assumed but not be proven.

Participating health care institutions were not randomized to different mask policies, but were free to choose their mask strategy. Even though we adjusted our analysis for different confounding factors, the results might have 
been affected by the non-randomized study design. As $\mathrm{HCW}$ were not exclusively exposed to SARS-CoV-2 at work, but also during non-occupational activities, the beneficial effect of FFP-2 masks for occupational safety might have been overlaid by the effect of non-occupational factors. We would therefore like to highlight that our findings regarding the healthcare institutions' mask policy only apply during periods of heavy non-occupational SARS-CoV-2 exposure of $\mathrm{HCW}$. The higher COVID-19 incidence in the regions where HCI favoured a general use of FFP-2 masks might have additionally diluted the potential protective effect of FFP-2 masks for occupational SARS-COV-2 exposure. As part of the study we have not assed the compliance with mask policy and the other protective measure. Further, the effect of FFP-2 masks in our study may have been limited by scant instructions for safe use of these devices. Especially the lack of systematic mask fitting tests may have affected our results. The inconvenience associated with wearing FFP-2 masks may have also hampered the compliance of employees of the respective healthcare institutions.

\section{Conclusions}

We identified that exposure to SARS-CoV-2 household members was the risk factor with the strongest association for seroconversion among $\mathrm{HCW}$. In addition, HCW with direct exposure to COVID-19 patients were at increased risk for seroconversion. Despite this finding, the healthcare institutions' mask policy (surgical face masks type IIR vs. FFP-2 masks) had no effect on the proportion of seropositive health care employees at the respective institution during this pandemic with heavy non-occupational SARS-CoV-2 exposure.

\footnotetext{
Abbreviations

AGP: Aerosol-generating procedures; CDC: Centers for diseases control and prevention; Cl: Confidence interval; COI: Cutoff index (COI); COVID-19: Corona virus disease-2019; ECDC: European centre for disease prevention and control; ECLIA: Electro-chemiluminescence immunoassay; FFP-2: Filtering face piece class-2; FOPH: Federal office of public health $(\mathrm{FOPH})$; $\mathrm{HCl}$ : Health care institutions; HCW: Health care workers; IgG: Immunoglobulin G; mL: Milliliter; OR: Odds ratio; aOR: Adjusted odds ratio; $p$ : P-value; PCR: Polymerase chain reaction; PPE: Personal protective equipment (PPE); SARS-CoV-2: Severe acute respiratory syndrome coronavirus 2; Swissnoso: Swiss national center for infection control; WHO: World Health Organization (WHO.
}

\section{Supplementary Information}

The online version contains supplementary material available at https://doi. org/10.1186/s13756-021-01047-x.

Additional file 1. Supplementary Data.

\section{Acknowledgements}

We thank all study participants, nurses, laboratory technicians and physicians for their commitment and Arnold Bachmann for his great support of the AMICO Study.
The authors of the AMICO Study Group are: Vedat Eronat, Regional Hospital of Bregaglia, Switzerland. Luwina Eichweber, Regional Hospital of Savognin, Switzerland. Theodor von Fellenberg, Regional Hospital of Val Müstair, Switzerland. Mauro Albertini, Regional Hospital of Poschiavo, Switzerland. Gian Flury, Regional Hospital of Scuol, Switzerland. Marie-Charlotte Brüggen, Hochgebirgsklinik Davos, Switzerland. Andres Schneeberger, Psychiatric Services of Canton Grisons, Chur, Switzerland. Thomas Koch, Regional Hospital of Ilanz, Switzerland. Michele Genoni, Rehabilitation Clinic of Seewis, Switzerland. Walter Kistler, Regional Hospital of Davos, Switzerland. Patrick Egger, Regional Hospital of Samedan, Switzerland.

\section{Authors 'contributions}

$\mathrm{KZ}$ : was involved in recruitment of study participants, data analysis and writing of the article, FF: was involved in study planning and organizing, SH and MR were involved in study planning and were responsible for the serologic testing in the laboratory, TB: was responsible for information communications technology regarding the online-questionnaire, $\mathrm{VL}$ : was involved in data analysis and revision of the article, SG: performed the statistical analyses, $\mathrm{CH}$ : was involved in data analysis and revision of the article, AC: contributed to concept, design and writing of the article. All authors read and approved the final manuscript.

\section{Funding}

The study was funded by the Cantonal Hospital of Grisons and the participating health care institutions.

\section{Availability of data and materials}

The datasets used and/or analysed during the current study are available from the corresponding author on reasonable request.

\section{Declarations}

\section{Ethical approval and consent to participate}

The study was approved by the ethics committee of the canton Zurich. (BASEC-No.: 2020-01322). Written informed consent was obtained from all participants before enrolment.

\section{Consent for publication}

Not applicable.

\section{Competing interests}

The authors declare that they have no competing interests.

\section{Author details}

${ }^{1}$ Department of Internal Medicine, Cantonal Hospital of Grisons, Chur, Switzerland. ${ }^{2}$ Division of Infectious Diseases, Cantonal Hospital of Grisons, 7000 Chur, Switzerland. ${ }^{3}$ Central Laboratory, Cantonal Hospital of Grisons, Chur, Switzerland. ${ }^{4}$ Division for Information and Communication Technology, Cantonal Hospital of Grisons, Chur, Switzerland. ${ }^{5}$ Division of Nephrology, Cantonal Hospital of Grisons, Chur, Switzerland. ${ }^{6}$ Clinical Trials Unit, Cantonal Hospital of St. Gallen, St. Gallen, Switzerland. ${ }^{7}$ Department of Infectious Diseases and Hospital Epidemiology, University Hospital and University of Bern, Bern, Switzerland.

Received: 15 July 2021 Accepted: 24 December 2021

Published online: 10 January 2022

\section{References}

1. Korth J, Wilde B, Dolff S, Frisch J, Jahn M, Krawczyk A, et al. SARS-CoV-2 seroprevalence in healthcare workers in Germany: a follow-up study. Int J Environ Res Public Health. 2021;18(9):4540.

2. Sikkema RS, Pas SD, Nieuwenhuijse DF, O'Toole Á, Verweij J, van der Linden A, et al. COVID-19 in health-care workers in three hospitals in the south of the Netherlands: a cross-sectional study. Lancet Infect Dis. 2020;20(11):1273-80.

3. Talbot LR, Romeiser UL, Spitzer ED, Gan TJ, Singh SM, Fries BC, et al. Prevalence of IgM and IgG antibodies to SARS-CoV-2 in health care workers 
at a tertiary care New York hospital during the Spring COVID-19 surge. Perioper Med (Lond). 2021;10(1):7.

4. Rashid-Abdi M, Krifors A, Salleber A, Eriksson J, Mansson E. Low rate of COVID-19 seroconversion in health-care workers at a Department of Infectious Diseases in Sweden during the later phase of the first wave; a prospective longitudinal seroepidemiological study. Infect Dis (Lond). 2021;53(3):169-75.

5. Lidstrom AK, Sund F, Albinsson B, Lindback J, Westman G. Work at inpatient care units is associated with an increased risk of SARS-CoV-2 infection; a cross-sectional study of 8679 healthcare workers in Sweden. Upsala J Med Sci. 2020;125(4):305-10.

6. Nygren D, Noren J, De Marinis Y, Holmberg A, Fraenkel CJ, Rasmussen M. Association between SARS-CoV-2 and exposure risks in health care workers and university employees - a cross-sectional study. Infect Dis (Lond). 2021;53(6):460-8.

7. Iversen K, Bundgaard H, Hasselbalch RB, Kristensen JH, Nielsen PB, PriesHeje M, et al. Risk of COVID-19 in health-care workers in Denmark: an observational cohort study. Lancet Infect Dis. 2020;20(12):1401-8.

8. Wilkins JT, Gray EL, Wallia A, Hirschhorn LR, Zembower TR, Ho J, et al. Seroprevalence and correlates of SARS-CoV-2 antibodies in health care workers in Chicago. Open Forum Infect Dis. 2021;8(1):ofaa582.

9. Lai X, Wang M, Qin C, Tan L, Ran L, Chen D, et al. Coronavirus disease 2019 (COVID-2019) infection among health care workers and implications for prevention measures in a tertiary hospital in Wuhan, China. JAMA Netw Open. 2020;3(5):e209666

10. Eyre DW, Lumley SF, O'Donnell D, Campbell M, Sims E, Lawson E, et al. Differential occupational risks to healthcare workers from SARS-CoV-2 observed during a prospective observational study. Elife. 2020;9:e60675.

11. Kahlert CR, Persi R, Gusewell S, Egger T, Leal-Neto OB, Sumer J, et al. Nonoccupational and occupational factors associated with specific SARSCoV-2 antibodies among hospital workers-a multicentre cross-sectional study. Clin Microbiol Infect. 2021;27(9):1336-44.

12. Conly J, Seto WH, Pittet D, Holmes A, Chu M, Hunter PR, et al. Use of medical face masks versus particulate respirators as a component of personal protective equipment for health care workers in the context of the COVID-19 pandemic. Antimicrob Resist Infect Control. 2020;9(1):126.

13. Chu DK, AkI EA, Duda S, Solo K, Yaacoub S, Schunemann HJ, et al. Physical distancing, face masks, and eye protection to prevent person-to-person transmission of SARS-CoV-2 and COVID-19: a systematic review and meta-analysis. Lancet. 2020;395(10242):1973-87.

14. Buonanno G, Morawska L, Stabile L. Quantitative assessment of the risk of airborne transmission of SARS-CoV-2 infection: prospective and retrospective applications. Environ Int. 2020;145:106112.

15. Morawska L, Milton DK. It is time to address airborne transmission of coronavirus disease 2019 (COVID-19). Clin Infect Dis. 2020;71(9):2311-3.

16. WHO. Mask use in the context of COVID-19. Interim guidance. 2020. Avaliable at: https://apps.who.int/iris/handle/10665/337199. Accessed 11 July 2021.

17. Public. Health England. Guidance COVID-19: infection prevention and control (IPC), last update 1 June 2021. Available at https://www.gov.uk/ government/publications/wuhan-novel-coronavirus-infection-preve ntion-and-control. Accessed 11 July 2021.

18. Swissnoso update recommendation on the use of FFP2 respirators for healthcare workers with direct contact to COVID-19 patients in acute care hospitals, June 2021. Available at https://www.swissnoso.ch/forsc hung-entwicklung/aktuelle-ereignisse/ Accessed 11 July 2021.

19. CDC. Using personal protective equipment (PPE). Updated 19 Aug 2020 Available at https://www.cdc.gov/coronavirus/2019-ncov/hcp/usingppe.htmlv. Accessed 11 July 2021

20. ECDC. Infection prevention and control and preparedness for COVID19 in healthcare settings. Sixth update -9 February 2021. Available at https://www.ecdc.europa.eu/en/publications-data/infection-preventionand-control-and-preparedness-covid-19-healthcare-settings. Accessed 11 July 2021

21. The Robert Koch Institute. Empfehlungen des RKI zu Hygienemaßnahmen im Rahmen der Behandlung und Pflege von Patienten mit einer Infektion durch SARS-CoV-2. Last updated: 22 Feb 2021. https://www. rki.de/DE/Content/InfAZ/N/Neuartiges_Coronavirus/Hygiene.html;jsess ionid=B97C38C 15306C356580447EABD6B3234.internet071?nn=23862 28 Accessed 11 July 2021
22. Wilson NM, Marks GB, Eckhardt A, Clarke AM, Young FP, Garden FL, et al. The effect of respiratory activity, non-invasive respiratory support and facemasks on aerosol generation and its relevance to COVID-19. Anaesthesia. 2021;76:1465-74.

23. Cheng Y, Ma N, Witt C, Rapp S, Wild PS, Andreae MO, Pöschl U, Su H. Face masks effectively limit theprobability of SARS-CoV-2 transmission. Science. 2021;eabg6296. https://doi.org/10.1126/science.abg6296.

24. Hamilton F, Arnold D, Bzdek BR, Dodd J, Group A, Reid J, et al. Aerosol generating procedures: Are they of relevance for transmission of SARSCoV-2? Lancet Respir Med. 2021;9(7):687-9.

25. https://www.gr.ch/DE/institutionen/verwaltung/djsg/ga/coronavirus/ info/Seiten/Start.aspx Accessed 11 July 2021.

26. Elecsys-Anti-SARS-CoV-2-factsheet. https://diagnostics.roche.com/ch/de/ products/params/elecsys-anti-sars-cov-2.html Accessed 11 July 2021.

27. Federal Office of Public Health. https://bag-coronavirus.ch/ Accessed 11 July 2021.

28. Shah ASV, Wood R, Gribben C, Caldwell D, Bishop J, Weir A, et al. Risk of hospital admission with coronavirus disease 2019 in healthcare workers and their households: nationwide linkage cohort study. BMJ. 2020:371:m3582.

29. Haller S, Güsewell S, Egger T, Scanferla G, Thoma R, Leal-Neto OB, et al. Use of respirator vs. surgical masks in healthcare personnel and its impact on SARS-CoV-2 acquisition-a prospective multicentre cohort study. medRxiv. 2021;21:e112.

30. Zhao J, Yang Y, Huang H, Li D, Gu D, Lu X, et al. Relationship between the ABO blood group and the COVID-19 susceptibility. Clin Infect Dis. 2020;29:90.

\section{Publisher's Note}

Springer Nature remains neutral with regard to jurisdictional claims in published maps and institutional affiliations.

Ready to submit your research? Choose BMC and benefit from

- fast, convenient online submission

- thorough peer review by experienced researchers in your field

- rapid publication on acceptance

- support for research data, including large and complex data types

- gold Open Access which fosters wider collaboration and increased citations

- maximum visibility for your research: over $100 \mathrm{M}$ website views per year

At BMC, research is always in progress.

Learn more biomedcentral.com/submissions 